\title{
GENERASI ISLAM BERLANDASKAN BHINEKA TUNGGAL IKA
}

\author{
Mohammad Anggih Alif
}

\author{
Pendidikan Guru Sekolah Dasar \\ Fakultas Keguruan dan Ilmu Pendidikan \\ Universitas Nahdlatul Ulama Sidoarjo \\ Email: mohammadalif077@gmail.com
}

\section{Pengantar}

Islam merupakan agama yang Rahmatan lil Alamin atau agama yang menebar kasih sayang kepada seluruh makhluk ciptaan Allah SWT serta agama yang diridhoi oleh Allah SWT, seperti yang terkandung dalam surah Ali Imron ayat 19 yakni: "Innaddina 'Indallahil Islam" artinya sesungguhnya agama yang diridhoi Allah SWT hanyalah Islam. Ajaran agama Islam dibawahkan oleh para Nabi dan Rasul dengan cara dakwah secara diam-diam maupun secara terang-terangan dan penuh suka duka dalam menyampaikan agama Islam, namun Islam mengalami perkembangan pesat pada saat Nabi Muhammad SAW memimpin Islam dan diteruskan para Khulafahur Rosyidin yakni: Abu Bakar Ash-Shidiq, Umar Bin Khattab, Utsman Bin Affan serta Ali Bin Abi Thalib, lalu dilanjutkan kepimpinannya serta ajaran agama Islam oleh kerajaan-kerajaan Islam sampai kepenjuruh dunia termasuk Indonesia.

Seno Aji (2018) menjelaskan bahwa agama Islam masuk ke Indonesia ada empat teori yakni Teori Gujarat yang beranggapan bahwa Islam berasal dari daerah Gujarat, India yang dibawah oleh para pedagang yang melaut menuju selat Malaka pada abad ke-13 melalui komunikasi antara pedagang dengan kerajaan samudra pasai yang mendominasi daerah selat malaka pada saat itu, hal itu didukung oleh invensi yang dilakukan oleh S. Hurgronje dan J. Pijnapel terhadap makam sultan Malik As-Saleh (salah satu sultan kerajaan samudra pasai) pada tahun 1927 M yang bercorak Gujarat.

Dia mengutip Teori Persia dari Umar Amir H dan Hoesein Djadjadiningrat yang mengatakan agama Islam masuk ke Nusantara melalui para pedagang Persia/Iran bukan berasal dari Gujarat, hal ini dibuktikan dengan adanya kemiripan ajaran agama Islam Indonesia dengan ajaran Islam Syiah di Persia/Iran dan juga kemiripan tradisi yang dimiliki Indonesia dengan yang ada di Persia/Iran, yakni memperingati bulan 10 Muharram dan juga memperingati gugurnya Sayyidina Husain Bin Ali cucu Nabi Muhammad SAW yang meninggal saat berperang di Karbala yang biasanya disebut Tabuik/Tabut.

Dia mengutip Teori China dari Slamet Mulyana dan Sumanto Al Qurtuby yang berpendapat bahwa kebudayaan Islam yang masuk ke Nusantara melalui perantara masyarakat muslim China, hal ini dibuktikan dengan banyaknya masyarakat muslim China dari kanton yang migrasi ke Nusantara (Palembang) pada abad ke9, hal ini diperkuat dengan bukti kuat bahwasannya Raden Patah (Raja Demak) merupakan keturunan China. 
Dia menjelaskan Teori Makkah menjelaskan bahwa Islam yang berada di Nusantara dibawah para musafir dari Arab pada abad ke-7 dengan tujuan menyebarkan agama Islam ke seluruh dunia, hal ini dibuktikan dengan adanya kampung Arab di Barus, Sumatra Utara yang bernama Bandar Khalifah, tidak hanya itu di daerah kerajaan Samudra Pasai menganut faham Mahzab Imam Syafii terkenal juga di Arab dan Mesir. Kata Al-Malik merupakan gelar yang digunakan oleh para raja Samudra Pasai yang menyerupai kebudayaan Islam di Mesir, hal ini didukung oleh para tokoh yakni Van Leur, Anthony H. Johns, T. W Arnold serta Buya Hamka.Agama Islam mengajarkan kepada setiap umat Islam untuk saling menghormati dan menghargai perbedaan yang ada di bangsa kita, hal ini memunculkan pemikiran bangsa Indonesia untuk mencetuskan semboyan bangsa yakni "Bhineka Tunggal Ika" agar perbedaaan yang ada di Indonesia tidak menimbulkan perpecahan maupun permusahan, hal ini tercantum dalam surah AlHujurat ayat 13 yang artinya: "Hai manusia, sesungguhnya kami menciptakan kamu dari seorang laki-laki dan seorang perempuan dan menjadikan kamu berbangsa-bangsa dan suku-suku supaya kamu saling mengenal, sesungguhnya orang yang paling mulia diantara kamu di sisi Allah SWT ialah orang yang paling bertakwa kepada di antara kamu, sesungguhnya Allah SWT maha mengetahui lagi maha mengenal".

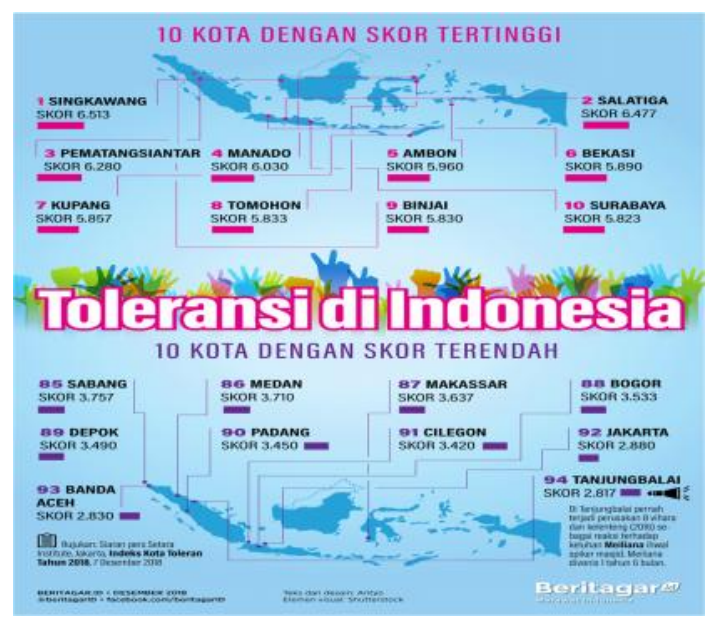

Gambar 1. Daftar kota dengan skor toleransi tertinggi sampai terendah (Beritagar, 2018)

Bahwa setiap manusia yang ciptakan oleh Allah SWT itu berbeda-beda, supaya antar manusia itu saling mengenal dan melengkapi kekurangan yang dimiliki bukan menjadikan perbedaan itu sebagai permusuhan.

\section{Nabi Ibrahim AS Mencetak Generasi Anak Sholeh}

Di agama Islam sudah contoh atau suri tauladan dalam masalah pendidikan keluarga yakni Nabi Ibrahim AS. Taqin Muhammad (2018) menjelaskan bahwa ada tiga fase yang dijalani Nabi Ibrahim AS dalam menantikan kelahiran anak yang di inginkan selama sekian tahun, yang pertama adalah sebelum memiliki anak, kedua adalah penantian kelahiran seorang anak, ketiga adalah saat memiliki anak, pada fase pertama, Nabi Ibrahim mempersiapkan lingkungan yang baik untuk sang anak agar mendapatkan pendidikan baik pula, maksudnya ketika Nabi 
Ibrahim AS menikah dengan Siti Sarah dan Siti Hajar yang merupakan perempuan yang baik dan secara tidak sengaja Nabi Ibrahim AS sudah menemukan lingkungan yang baik untuk membesarkan anak-anaknya, dan Nabi Ibrahim AS juga membuat lingkungan tempat tinggal yang baik dengan membuatkan baitullah atau masjid supaya anak-anaknya selalu mengingat Allah SWT.

Pada fase kedua, ketika Nabi Ibrahim AS menikahi Siti Sarah dan Siti Hajar, pasangan ini belum memiliki anak akan tetapi pasangan tersebut tidak berputus asa, walaupun sudah lama menanti anak yang di inginkan, akhirnya Nabi Ibrahim AS berdoa kepada Allah SWT agar dikaruniai seorang anak yang sholeh, dan ini adalah doa Nabi Ibrahim AS ketika meminta dikaruniai anak yang sholeh: "Robbi Habli Minassholihin", dan artinya: "Ya Tuhanku, berilah aku keturunan yang saleh", dalam hal ini yang diminta Nabi Ibrahim AS hanyalah anak yang sholeh bukan anak yang kelak menjadi orang yang berlimpah harta, dan ada doa Nabi Ibrahim AS agar anak turunnya patuh yang tercantum dalam Al-Qur' an surah AlBaqarah ayat: 128 yang artinya "Ya Tuhan kami, jadikanlah kami berdua, orang yang tunduk kepada Engkau dan (jadikanlah) diantara anak cucu kami, umat yang tunduk patuh kepada Engkau....".

Pada fase ketiga, disaat Nabi Ibrahim AS sudah dikaruniai anak, Nabi Ibrahim AS mengajar ilmu agama islam dan cara ibadah kepada kedua anaknya supaya ketika mereka dewasa bisa menerapkan dengan baik dan benar dan Nabi Ibrahim AS juga mengajak anaknya untuk bermusyawarah atau berdialog supaya anak dapat mengungkapkan pendapat yang akan memunculkan rasa percaya diri.

\section{Amalan dan Doa Meminta Anak Sholeh maupun Sholehah}

Setiap pasangan pasti menginginkan kehadiran seorang anak apalagi memiliki sifat yang sholeh maupun sholehah dan pasangan tersebut pasti akan melakukan segala cara untuk mencapai hal tersebut, dalam hal ini Hafizi Azmi (2018) berpendapat ada lima amalan untuk mendapatkan anak yang sholeh maupun sholehah yakni:

Pertama "berdoa ketika akan melakukan hubungan suami istri", jika ingin mendapatkan anak yang sholeh maupun sholihah dan baik, ada suatu anjuran dari Rasulullah SAW yakni sebuah doa sebelum melakukan hubungan suami istri: "Bismillahi Allahumma Jannibnasy Syaithana Wajannibisy Syaithana Maa Razaqtanaa", dan artinya: "dengan menyebut nama Allah SWT, Ya Allah jauhkanlah kami dari campur tangan setan dan jauhkan pula setan dari apa-apa yang engkau karuniakan kepada kami”, kenapa harus doa ini yang di baca, Rasulullah SAW bersabda “jika diantara kalian berjima' seraya berdoa, Wahai Allah SWT jauhkanlah setan dari kami, Ya Allah jauhkanlah kami dari campur tangan setan dan jauhkan pula setan dari apa yamg engkau karuniakan kepada kami. Maka jika ditentukan bagi mereka (anak), tak akan di perangkap oleh setan selama-lamanya", (Hadits riwayat Bukhari).

Kedua "amalkan doa meminta anak sholeh yang dilafadkan oleh para nabi", kenapa semua perbuatan kita harus mencerminkan perbuatan para Nabi, sebab Nabi merupakan manusia pilihan Allah SWT dan ketika para Nabi memanjatkan 
doa, doanya langsung dikabulkan oleh Allah SWT, ada tiga doa para Nabi yang tercantum di dalam Al-Qur'an yakni: pertama "Rabbi habli minassholihin" yang artinya: "Ya Tuhanku, anugerahkanlah kepadaku (seorang anak) yang termasuk orang-orang yang sholeh" (Al-Qur'an surah As-Saffat ayat 100), doa ini merupakan doa yang panjatkan oleh Nabi Ibrahim AS, kedua "Rabbana hablana min azwajina wa dzurriyatina qurrota a'yun waj'alna lil muttaqina imama” yang artinya: "Ya Tuhan kami, anugerahkanlah kami kepada istri-istri kami dan keturunan kami sebagai penyenang hati (kami) dan jadikanlah kami imam bagi orang-orang yang bertaqwa" (Al-Qur'an surah Al-Furqon ayat 74) doa ini merupakan doa meminta kebaikan pada anak dan istri, dan yang ketiga "Rabbi hablii min ladunka dzurriyyatan thoyyiban, innaka samii'ud du'aa" yang artinya: "Ya Tuhan ku, berilah aku dari sisi engkau seseorang anak yang baik. Sesungguhnya engkau maha pendengar doa" (Al-Qur' an surah Ali Imron ayat 38) doa ini merupakan doa yang dipanjatkan oleh Nabi Zakaria AS, bagi pasangan suami istri yang berkeinginan cepat untuk mendapatkan seorang anak maka harus mengetahui waktu yang utama dalam melafadkan doa tersebut yakni: berdoa diantara adzan sampai iqomah, berdoa ketika menjelang buka puasa, berdoa ketika selesai menjalankan sholat lima waktu, berdoa di hari jum'at, dan berdoa ketika selesai sholat tahajud atau sepertiga malam, selain waktu berdoa hendaknya memperhatikan tempat ia dimana berdoa, yakni berdoa di depan ka'bah AlMukarromah dan di masjid Nabawi tepatnya di Raudhoh/Taman Surga disaat menjalani ibadah haji maupun umroh, jika belum mampu melakukannya cukup mengundang tetangga disekitar rumah untuk meminta bantuan doa agar cepat mendapatkan momongan.

ketiga "perbanyak berbuat amal kebaikan", karena Allah SWT suka kepada hambanya yang berbuat kebaikan meskipun kecil tetapi konsisten, maka dari itu ketika pasangan suami istri suka berbuat kebaikan kemungkinan kelak anak mereka pasti akan meniru perbuatan yang dilakukan oleh kedua orangtuanya, ada sebuah pepatah yang menerangkan bahwa anak merupakan cerminan kedua orangtuanya, selain itu para pasangan suami istri juga harus berprasangka baik kepada Allah SWT, karena ketika mereka ditimpah suatu masalah dan berakhir yang tidak sesuai dengan keinginan mereka, maka ingatlah Allah SWT sebab takdir Allah SWT lebih baik daripada kehendak manusia.

keempat "bersungguh-sungguh dalam ikhtiar dan usaha" ketika pasangan suami istri berkeinginan mempunyai anak yang sholeh maupun yang sholehah harus seimbang antara ikhtiar kepada Allah SWT dan usaha secara medis, sebab jika hanya salah satu yang dijalankan maka kemungkinan mendapatkan anak yang sholeh maupun sholehah bisa jadi tidak akan terlaksana, maka dari itu antara ikhtiar kepada Allah SWT dengan cara melakukan perbuatan baik, rajin beribadah/sering-sering berdoa, dan menjauhi apa yang dilarang oleh Allah SWT dan Rasulullah SAW serta usaha secara medis dengan cara berkonsultasi kepada 
dokter tentang memeriksakan kandungan, memastikan masa kesuburan pasangan, dan menjalankan program-program yang dapat mempercepat kehamilan.

kelima "tawakal dan sabar" ketika segala usaha telah dilakukan akan tetapi hasilnya tidak seperti yang diinginkan, ingatlah bahwa kita tetap harus berprasangka baik dan yakin kepada Allah SWT karena dialah sang pembuat rencana-rencana yang baik bagi hambanya.

\section{Pengenalan Ukhuwah Kepada Anak}

Ahmad Zainul Hamdi (2018) menjelaskan arti ukhuwah secara singkat ialah persaudaraan sesama manusia, dalam hal ini Ahmad Zainul Hamdi mengutip rumusan KH. Achmad Sidiq (mantan Rois Aam Syuriah NU Jawa Timur tahun 1984-1991) yang menjelaskan bahwa ada tiga rumusan ukhuwah yakni

Pertama "Ukhuwah Islamiyah" adalah persaudaraan sesama orang muslim, bahwasannya sebagai orangtua, wajib memberi tahukan kepada sang anak bahwa kamu dilahirkan sebagai orang islam, harus saling mengenal sesama orang islam, dan sebagai islam harus saling tolong menolong serta tidak saling bertengkar, hal ini dijelaskan pada sebuah hadist Nabi Muhammad SAW yang menerangkan bahwa "sesungguhnya seorang mukmin dengan mukmin lainnya seperti bangunan yang saling menguatkan satu sama lain....." (hadits riwayat muslim no. 4023).

kedua "Ukhuwah Wathaniyah" adalah persaudaraan sesama warga bangsa (Indonesia), ketika anak sudah mengenal lingkungan keluarga maka kita sebagai orangtua harus mengenalkan anak kepada lingkungan masyarakat supaya dia tidak menjadi orang yang individu dan para orangtua harus juga menerangkan tentang keadaan yang ada di masyarakat, misalnya: menjelaskan tentang dari daerah mana tetangga kita, agama mereka apa, supaya anak tahu bahwa dia tinggal di daerah yang multicultural (beragam budaya) dan dapat menumbuhkan rasa nasionalisme pada anak serta dapat menumbuhkan rasa toleransi pada anak tentang perbedaan ada di lingkungan masyarakat.

ketiga "Ukhuwah Basyariyah" adalah persaudaraan sesama manusia (universal), ketika anak sudah bisa diajak untuk berfikir maka para orangtua harus memberi wawasan kepada sang anak bahwasannya di dunia ini tidak terbatas hanya ada agama islam dan negara Indonesia akan tetapi diluar sana masih banyak lagi macam-macam negara dengan ciri khas masing dan berbagai macam agama, hal ini dapat memunculkan rasa ingin tahu yang besar serta dapat memicu aktifitas otak anak untuk berimajinasi tentang dunia, dan sebagai orangtua harus memberikan fasilitas untuk mendukung aktifitas otak anak, yakni dengan melihatkan video tentang perkembangan manusia dari zaman dulu hingga sekarang dan orang tua bisa mengajak anaknya ke tempat bersejarah yang ada di Indonesia maupun di luar negeri. 


\section{Pendidikan Pancasila}

Selain pendidikan agama anak juga harus diberi pendidikan Pancasila supaya dia tidak mudah terjerumus kepada gerakan islam yang ekstrim, pada hal ini saya akan menjelaskan tentang pendidikan Pancasila adalah sebuah pengajaran yang bersumber dari nilai-nilai pada masing-masing sila yang terdapat pada Pancasila yang saya kutip dari Fikri Zulal (2018) yakni:

Pertama "nilai ketuhanan" jadi para orangtua menerangkan kepada anak mereka bahwasannya Indonesia itu memiliki berbagai macam agama oleh karena itu orangtua perlu menanamkan pemahaman toleransi antar agama kepada anaknya.

kedua "nilai kemanusiaan" jadi orangtua menerangkan kepada anak mereka bahwasannya manusia memiliki hak atau kepemilikan yang harus dihormati oleh semua orang tanpa ada yang bisa menggugatnya dan sebagai mana manusia kita diwajib taat kepada norma atau peratuaran yang berlaku di masyarakat supaya tercapainya ketertiban masyarakat.

ketiga "nilai persatuan" bahwasannya anak harus tahu bahwa Indonesia ini merupakan sekumpulan bangsa yang dijadikan satu negara maka dari itu Indonesia disebut negara yang multicultural (beragam budaya) di setiap daerahnya dari Sabang sampai Merauke, dari Miana sampai Pulau Rote, yang harus diajarkan oleh orangtua kepada anaknya ialah sikap menghargai atau toleransi terhadap perbedaan yang ada di bangsanya.

keempat "nilai kerakyatan" bahwasannya kebijakan pemerintah itu digunakan untuk kepentingan kesejahteraan rakyatnya, misalnya: ketika anak sakit, orangtua langsung membawa anak ke rumah sakit atau puskesmas terdekat walaupun keadaan keluaraga tersebut dalam keadaan miskin tetapi pemerintah telah memberi bantuan berupa kartu bpjs untuk berobat ke rumah sakit atau puskesmas terdekat, dari contoh diatas ada pembelajaran yang bisa diberikan kepada anaknya yakni menghormati pemimpin yang sedang menjalankan roda pemerintahan, artinya anak di didik untuk menghormati kebijakan pemimpin suatu negara dan tidak melanggar aturan yang sudah ditetapkan.

kelima "nilai keadilan" bahwasannya orangtua wajib menerapkan prinsip keadilan kepada anak supaya mereka ketika dewasa tidak mengambil hak yang bukan miliknya.

\section{Cinta Tanah Air}

Ketika anak sudah memahami negerinya sendiri maka akan muncul sikap cinta tanah air, apa yang dimaksud dengan cinta tanah air, menurut Idris Kamisopa (2017) menjelaskan bahwa cinta tanah air adalah mencintai bangsa sendiri maksudnya adalah apapun yang ada maupun dihasilkan oleh Indonesia wajib kita bangga dan sekaligus kita juga menikmati hasilnya, dalam hal ini orangtua bisa mencontohkan bagaimana cara cinta tanah air kepada anaknya, missal: orangtua mengajak anak ke pasar tradisional untuk membeli baju batik, dari contoh tersebut 
dapat disimpulkan bahwa orangtua harus menanamkan rasa cinta tanah air kepada anaknya sejak kecil supaya tidak terpengaruh oleh budaya maupun produk luar negeri.

\section{Penutup}

Bahwa sesungguhnya semua pasangan suami istri berkeingin memiliki anak yang sholeh maupun sholehah apalagi bisa bermanfat bagi menjaga keutuhan bangsa maka dari itu setiap pasangan melakukan segala cara untuk mencapai apa yang diinginkan mulai dari meniru amalan yang diajarkan oleh agamanya sampai berkonsultasi kepada dokter, ketika segala usaha telah dilakukan akan tetapi hasilnya tidak memuaskan, ingatlah bahwa Allah SWT adalah pembuat rencanarencana yang terbaik bagi hambanya, kemudian harapan itu akhirnya terwujud dan tugas orangtua semaking berat yakni: menjaga anak, memenuhi segala kebutuhan anak serta memfasilitasi pendidikan sang anak, ada dua cara agar anak menjadi "generasi islam yang berlandaskan bhineka tunggal ika", yakni religious dan budaya, apabila ini bisa berjalan bersamaan maka misi mewujudkan "generasi islam yang berlandaskan bhineka tunggal ika" pasti akan terwujud.

\section{Refrensi}

Antyo, R. (2018). Toleransi di Indonesia. Retived December 25, 2018, from https://beritatagar.id/artikel/berita/kota/-berindeks-toleran-rendah-itumenyanggah-hasil

Eko, S. (2018). Kumpulan Hadits Tentang Persaudaraan Sesama Islam. Retived December 27, 2018, from

https://www.catatanmoeslimah.com/2018/08/kumpulan-hadits-tentang-

persaudaraan-sesama-muslim.html

Fikri, Z. (2018). Nilai-Nilai Yang Terkandung dalam Pancasila. Retived Decesmber 27, 2018, from http://www.academia.edu/9465488/NILAI_NILAI_YANG_TERKANDUNG_DALAM_PANCASILA

Hafiz, A. (2018). Amalan Doa meminta Anak Sholeh dan Sholehah. Retived December 26, 2018, from

https://hafiziazmi.com/doa-meminta-anak-sholeh/

Idris, K. (2017). Cinta Tanah Air, Retived December 27, 2018, from

https://www.kompasiana.com/idriskamisopa/5929804f8e7e61c67214ba46/cintatanah-air

Rozali, NU Online. (2018). Menelaah Kembali Makna Ukhuwah. Retived December 27, 2018, from https://www.nu.or.id/post/read/98502/ukhuwah Seno, A. (2018). 4 Teori Masuknya Islam Ke Nusantara. Retived December 29, 2018, from 
https://www.google.com/amp/s/blog.ruangguru.com/4-teori-masuknya-islam-kenusantara\%3fhs_amp=true

Taqin, M. (2018). Cara Nabi Ibrahim AS Mendidik Anak. Retived December 25, 2018, from

https://abiummi.com/menjadi-orang-tua-teladan-dari-kisah-nabi-ibrahimalaihissalam 